\title{
Vocabulary Acquisition Through Multimedia In An Iraqi EFL Context
}

\author{
Asst. Lec. Suaad Abdul Ameer Meteab, Asst. Prof. Saadiya Wudaa Alquraishy \\ Administration of Education in Al-Qadissiyah. Suadabdulameer@gmail.com \\ University of Al-Qadisiyah, Iraq. saadiya.wydaa@qu.edu.iq
}

\begin{abstract}
The aim of this study is to investigate the effectiveness of using two types of multimedia techniques (PowerPoint and YouTube videos) on Iraqi EFL learners' vocabulary acquisition. To achieve the objective of this study, a Non- Randomized pre- post- test control group design has been used. The sample of the study consisted of 75 EFL learners at the intermediate level. The sample is divided into three groups: an experimental group 1 (25) learners, an experimental group 2 (25) learners and a control group (25) learners. The experimental group 1 was taught vocabulary by watching PowerPoint presentations, the experimental group 2 was taught vocabulary by watching YouTube videos, while the control group was taught by using the traditional method of teaching vocabulary. The results revealed that multimedia techniques have a positive influence on enhancing vocabulary acquisition.
\end{abstract}

Keywords:

Vocabulary acquisition, multimedia, incidental learning

Article Received: 18 October 2020, Revised: 3 November 2020, Accepted: 24 December 2020

\section{Introduction}

Along with the emergence of the communicative approach, the development of interactive media tools in English language Teaching has drew the attentions of teachers, educators and specialists. Brinton (2001), as cited in (Thao, 2003) stated that multimedia tools function as a significant stimulus in the process of language teaching for "media materials can lend authenticity to the classroom situation, reinforcing for students the direct relation between the language classroom and the outside world". Generally, multimedia learning, as Liakos and Diomidus (2002) define, is "the combination of visual and audio representations. These representations could include elements of texts, graphic arts, sound animation and video". It is defined similarly by Simkins et.al (2002) as the combination of objects of media such as texts, illustrations, videos, simulation, and sound for the purpose of representing and conveying information.

Multimedia learning, as tackled in this study founded on the words of Mayer (2001), is "the presentation of material using both words and pictures". He (ibid.) continues to elaborate that by words, the information can be presented verbally in a printed or /spoken text and by pictures it is presented in illustrative way by using inactive graphics like" illustrations, graphs, photos, or maps" or by the use of active graphics represented by the use of animations or videos.

Vocabulary awareness is usually seen as a vital device for learners of second language. It is maintained by Lin (2010) that "second learners who have limited vocabulary knowledge are less likely to be able to develop advanced levels of reading, listening, writing and speaking skills in the target language". Schmitt (2000) as cited in Alqahtani (2015) assures that "lexical knowledge is central to communicative competence and to the acquisition of a second language". Alqahtani (ibid.) has explained that effective communication in foreign language learning might be hindered when vocabulary items are inaccessible. The issue of the significance of vocabulary to language learners is also revealed by Nation (2004) as cited in Zahedia and Abdi (2012) when he considered it to be "the building blocks of a language since 
they label objects, actions, ideas without which people cannot convey the intended meaning".

The widespread view of vocabulary acquisition is deeply-rooted in Krashen's Input Hypothesis (1989) ,as cited in Hulstijn (2013). In an acquisition-learning distinction, Krashen (1989) began a range of studies that have tackled incidental or automatic vocabulary acquisition which can be referred to as "the acquisition of a word or expression without the conscious intention to commit the element to memory, such as 'picking up' an unknown word from listening to someone or from reading a text" as opposite to what labeled as intentional vocabulary learning that may arises as a result of deliberate effort and study.

Vocabulary learning is problematic, especially, for the nonnative learners of English who seem to face troubles concerning " the meanings of new words, spelling, pronunciation, correct use of words, guessing meaning through the context and so on". It is often characterized as the most problematic issue by language teachers and learners who may fail to communicate if they do not know the necessary word even though they know all the grammatical aspects of language (Afzal, 2019). Coady (1997) states that research that supports Krashen's claims positively concerning language vocabulary acquisition, is still inadequate. In this vein, the researchers of the current study see that the work on multimedia as a technique that can enhance incidental vocabulary acquisition, specifically with non-native learners can gain very good implications for effective foreign language learning vocabulary instruction.

In sum, based on what is stated by Paivio (1990) that learners can gain incidental unconscious recall of information when building meaningful communication between words and pictures and process information in stable in longterm memory, and on Mayer (2001) assumption that learners "learn better from words and pictures than from words alone, since dual association of information help learners create together verbal and pictorial mental models", the effect of using multimedia on vocabulary acquisition of Iraqi
EFL learners will be verified in this study. This justifies the use of PowerPoint and YouTube videos to be representative of multimedia learning where these both techniques intend to help learners acquire vocabulary without a cognitive load and to be retained in their long -term memory. Such techniques suit more the EFL teaching environment in Iraq where learners are given a teacher-centered language instruction, especially in learning vocabulary, is the prevailing form of teaching English in Iraq. Teachers still employ traditional approaches to teach English where learners lack the native teachers and direct interaction with them. Accordingly, this research study attempt to measure the effectiveness of these two techniques of multimedia, i.e., PowerPoint and YouTube videos on the learners' level of vocabulary acquisition in the Iraqi EFL context of at the intermediate level.

\section{Literature Review}

As a general definition multimedia means, as Najjar (1996) states, the use of "animation, pictures, video, and sound to present information". Multimedia is also defined by Mayer (2001) as a form of media with the purpose of presenting material where texts and images are combined. $\mathrm{He}$ then (ibid) refers to incorporation and merging of various mechanisms of media, like sound, simulation, text, illustrations, and video.

Sok (2014) sheds light on the role that multimedia plays in gaining incidental learning in vocabulary research, where learning of words arises naturally in the everyday life context, contrasting to intentional vocabulary learning where learning arises as a result of study with an intention. In the same vein, Kanellopoulou, Kermanidis, \& Giannakoulopoulos (2019) state that a basic component of fluent use of language is the user's ability to automatically identify words in listening and/or reading, in addition to having the ability to easily remember words when speaking or writing. When they are unknown, words cannot be used; thus, retrieval of this vocabulary with automaticity is a basic element vocabulary acquisition. They (ibid.) agree with 
Chun \& Plass (1996) as cited in Kabooha and Elyas (2018) that vocabulary have the tendency to be forgotten and that is why getting access to various resources of multimedia and technology can absolutely assist incidental vocabulary acquisition of learners as vocabulary learning with a combination of "pictorial and verbal cues" might support increasing the lexical items remembering and maintenance.

The vital usage of multimedia in vocabulary teaching is usually owed to its being built on the cognitive capacity of the brain where "mental imagery is the primary cognitive form of nonverbal representation" and this association between verbal and visual demonstrations of the content may arrive at a deeper understanding (Sadoski, 2005). Mayer (2009) and Mayer (2014) believes that the process of acquisition in multimedia is dependent on three suppositions:

1. Dual channels: the supposition commands that "humans possess separate channels for processing visual and auditory information".

2. Limited capacity: the supposition signifies that the processing of the material in the learners' working memory in each channel is not unlimited and consequently the learning task requires more cognitive processing than the ability of the processing system of the learner, then cognitive load arises.

3. The active-processing assumption states that learners do not absorb information passively but they need to be involved in lively cognitive processes to identify and select relevant material, organize it into visual / verbal models, and then integrating these new models with previous knowledge.

Many researchers assure the significant role of the use of PowerPoint as a type of multimedia in vocabulary acquisition that helps automatic recall of vocabulary. Nouri \& Shahid (2005), for example, admit that the "PowerPoint presentations should arouse the imagery system and could contribute to comprehension, and improve short and long-term memory". Other researchers like Radanov (2008) shows that learners like to be taught by the use of PowerPoint slides due to their accessibility, curiosity, and engaging setting. This engaging setting, as it is maintained by Idries (2016), can help learners to interact with the activities and consequently increase their comprehension of the words.

The second technique has been dealt with in this study is YouTube videos. Mayer (2001), as cited in Kabooha and Elyas (2015) see that the utilization of videos is fundamentally viable principally for elementary courses because it might simplify complicated conceptions, and attract the thoughts of lower-level learners. Heriyanto (2015) see that YouTube videos constitute a multidimensional source that deal with recordings in various types of information that can be forgotten easily. Moreover, YouTube videos are constrained in their lengths and this sorts them to be realistic and proper for the classroom's time. Similarly, Neuman and Koskinen (1992), as cited in Arndt and Woore (2018) indicate that "video materials can serve as useful input for incidental vocabulary learning and that this type of learning could lead to greater gains than reading in some receptive and productive aspects of vocabulary knowledge".

The use of multimedia in teaching vocabulary has been investigated by different researchers. Chun and Plass(1996), for example, have conducted three experiments to test the impact of three annotation techniques "texts, pictures, and videos" on vocabulary acquisition. Results of these experiments showed a higher rate on incidental learning of vocabulary. Hai-peng and Li-jing (2007) studied the effectiveness of multimedia technology on Vocabulary acquisition. They concluded that multi-media environment can improve the efficiency of vocabulary teaching and extend learners' vocabulary. Zarei and Gilanian(2013), on the other hand, studied the effect of the combination of video, audio, and captions on learners' vocabulary acquisition. They concluded that learning by the use of multimedia has a noticeable dominance over traditional learning. Mahmoudzadeh (2014) studied the impact of PowerPoint slides on the acquisition of abstract vocabulary. He concluded that the use of 
PowerPoint presentations has certain merits for learners, it can assist cooperative learning, in a way that the role of the teacher is not limited to supply learners with information, but enrolls them in the learning-teaching process. Azari and Giahpoor (2016) study examined the impact of multimedia on fifty two EFL learners in which they compared vocabulary gloss as incidental learning to paper gloss vocabulary learning. The results indicate that multimedia glosses have positive effect than paper glosses in learning vocabulary

\section{Hypothesis}

Three null hypotheses have been hypothesized, to achieve the purposes of the study:
1. There is no significant impact of using PowerPoint presentations on first intermediate Iraqi EFL learners' acquisition of vocabulary.

2. There is no significant impact of using YouTube videos on first intermediate Iraqi EFL learners' acquisition of vocabulary.

3. There is no significant difference between the experimental group 1 and the experimental group 2 in the acquisition of vocabulary.

\section{Methods}

\section{The Experimental Design}

To verify the hypotheses, the researchers has used the "Non- Randomized pre- post- test control group design " as it is shown in Table 1:

TABLE 1: The Experimental Design

\begin{tabular}{|l|l|l|c|}
\hline Group & Pre-Test & The Independent Variable & Post-Test \\
\hline Experimental 1 & Pre- test & Using PowerPoint presentations & post- test \\
\hline Experimental 2 & Pre-test & Using YouTube Videos & post- test \\
\hline Control & Pre- test & No technique is used & post- test \\
\hline
\end{tabular}

\section{Participants}

The experiment was conducted with first intermediate Iraqi EFL learners. In this context, learners are usually taught English by non- native teachers with an inadequate chances and situations to develop their English language literacy naturally since they hardly get the opportunities to interact with native speakers. It has also been observed that teachers at Iraq often employ traditional approaches of teaching vocabulary such as giving students list of words separately rather than utilizing contextualized authentic materials. Moreover, vocabulary learning process is very difficult and challenging for Iraqi EFL learners as they use their Arabic native language in all their daily life situations and use English language only inside their classes . So, the use of multimedia techniques may assist in finding a solution for this challenge.

The study sample consists of three sections of first intermediate learners studying English at Fatimat Al Zahraa Secondary School in Al-
Diwanyia Governorate of Iraq. Each section consists of 25 learners. The level of the learners is chosen intentionally by the researchers since first intermediate learners are considered to be less mature than their peers at the second and third levels. The whole ethical considerations have been put into considerations by the researchers and they were constructed under school staff supervision.

In order to get rid of any extraneous factors that may affect the outcomes of the study, the researchers have done their best to ensure the equivalence of three study groups. To check their equivalence in the level of vocabulary acquisition before starting the experiment, a pre-test has been applied to the participants of the study. The ANOVA analysis is applied and it has shown that the differences are statistically insignificant among the three groups at the degrees of freedom $(2.000,72.000)$ and the level of significance $(0.05)$ because the tabulated value (3.12) is higher than the computed one (0.109). This illustrates the equivalence of all the groups in their level of 
vocabulary acquisition in the pre-test, as found in

Table 2.

Table 2: ANOVA Results of the Three Study Groups in the Pre-test

\begin{tabular}{|c|c|c|c|c|c|c|c|c|}
\hline \multirow[t]{2}{*}{ no } & \multirow[t]{2}{*}{ variable } & \multirow{2}{*}{$\begin{array}{c}\text { The source } \\
\text { of the } \\
\text { contrast }\end{array}$} & \multirow{2}{*}{$\begin{array}{l}\text { Sum of } \\
\text { Squares }\end{array}$} & \multirow[t]{2}{*}{$\mathrm{df}$} & \multirow{2}{*}{$\begin{array}{l}\text { Mean } \\
\text { Square }\end{array}$} & \multicolumn{2}{|c|}{ F-value } & \multirow{2}{*}{$\begin{array}{c}\text { Sig. } \\
\text { at } 0.05\end{array}$} \\
\hline & & & & & & computed & tabulated & \\
\hline \multirow[t]{3}{*}{1} & \multirow[t]{3}{*}{$\begin{array}{l}\text { Vocabulary } \\
\text { Acquisition }\end{array}$} & $\begin{array}{c}\text { Between } \\
\text { Groups }\end{array}$ & 20.507 & 2.000 & 10.253 & \multirow{3}{*}{0.109} & \multirow{3}{*}{3.12} & \multirow{3}{*}{$\begin{array}{c}0.896 \\
\text { (insignificant) }\end{array}$} \\
\hline & & $\begin{array}{l}\text { Within } \\
\text { Groups }\end{array}$ & 6743.280 & 72.000 & 93.657 & & & \\
\hline & & Total & 6763.787 & 74.000 & & & & \\
\hline
\end{tabular}

\section{Procedures}

The entire period experiment lasted for six weeks during the academic year 2018-2019. The participants attended English classes for 45 minutes as a lesson period, 5 sessions a week. In order to check their current level of vocabulary, the three groups were pre-tested and the same test was conducted at the end of the experimental procedures.

Regarding the experimental group 1, the learners were exposed to PowerPoint presentations. Three presentations were given usually with texts and graphics of the vocabulary items targeted in their textbook. The PowerPoint presentation of the slides was given in a natural way without drawing out their attention to the meaning of the vocabulary.

In the experimental group 2, learners were exposed to YouTube videos. The researchers use laptop supported by LCD projector in order the videos to be watched clearly by them. The types of videos presented provide a connection between image, text and sound and these are linked together by a translation a matter which might help them in retention of lexical terms explored.

In the control group, learners participated in traditional English language classes where no additional information is received by them.

\section{Instruments}

A pre- post written test was used in this study for the sake of checking the learners' acquisition of vocabulary. The test consists of 60 items: 20 multiple- choice items, 20 true false items and 20 completion items. To obtain the test's validity, the researchers prepared the test according to the level of the learners. Then, it was exposed to a jury of experts in TEFL and Linguistics who admitted its validity. To achieve the test's reliability, Pearson correlation Coefficient was used the rate elicited is found to be 0.75 . Then, the Spearman-Brown prediction formula was used to recalculate the reliability, and the coefficient is found to be 0.79 .

\section{Results}

The pretest mean scores of the three groups, as Table 3 shows, were nearly at the same level in vocabulary acquisition. Comparison of the posttest mean scores of the three groups shows that the mean scores of both experimental groups are higher than those of the control group and that both experimental group1 (taught by using PowerPoint presentations) and experimental groups 2(taught by using YouTube videos) are nearly equivalent in their level of vocabulary acquisition (see Figure 1 and 2).

Table 3: Paired Difference between the Pre and Post written Test performance for the Three Groups

\begin{tabular}{|c|c|c|c|c|c|c|c|c|c|c|}
\hline \multirow{2}{*}{ no } & \multirow{2}{*}{ Group } & \multirow{2}{*}{ Variable } & \multicolumn{2}{|c|}{ Pre test } & \multicolumn{2}{|c|}{ Post test } & \multicolumn{2}{|c|}{ Paired Differences } & \multirow{2}{*}{ t-test } & \multirow{2}{*}{$\begin{array}{l}\text { Sig. } \\
\text { level } \\
\text { at }\end{array}$} \\
\hline & & & Mean & Std. & Mean & Std. & Mean & Std. & & \\
\hline
\end{tabular}




\begin{tabular}{|c|c|l|l|r|r|r|r|r|r|l|}
\hline & & & Deviation & & Deviation & & Deviation & & 0.05 \\
\hline 1 & Control & & 26.600 & 8.981 & 29.040 & 6.846 & -2.440 & 4.744 & 2.572 & 0.017 \\
\cline { 2 - 11 } 2 & $\begin{array}{c}\text { Experimental } \\
1\end{array}$ & $\begin{array}{c}\text { Vocabulary } \\
\text { Acquisition }\end{array}$ & 25.320 & 9.268 & 33.000 & 6.371 & -7.680 & 5.822 & 6.596 & 0.000 \\
\cline { 5 - 11 } 3 & $\begin{array}{c}\text { Experimental } \\
2\end{array}$ & & 25.920 & 10.696 & 37.880 & 5.790 & 11.960 & 11.692 & 5.115 & 0.000 \\
\hline
\end{tabular}

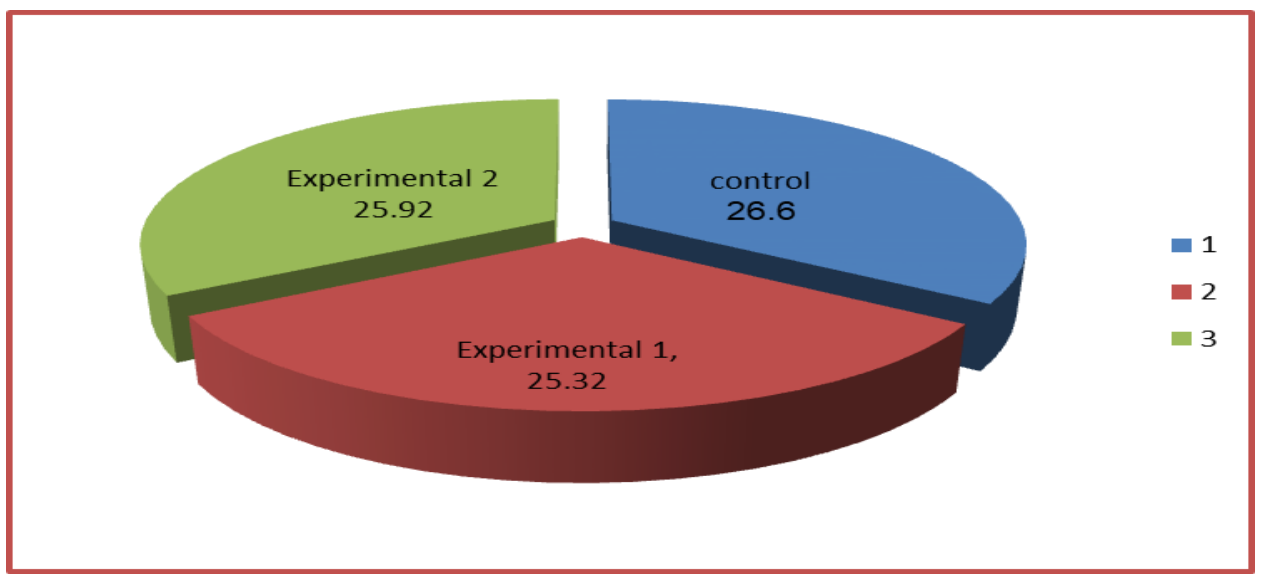

Figure 1

The Mean Score of the Study Groups in the Pre-written Test

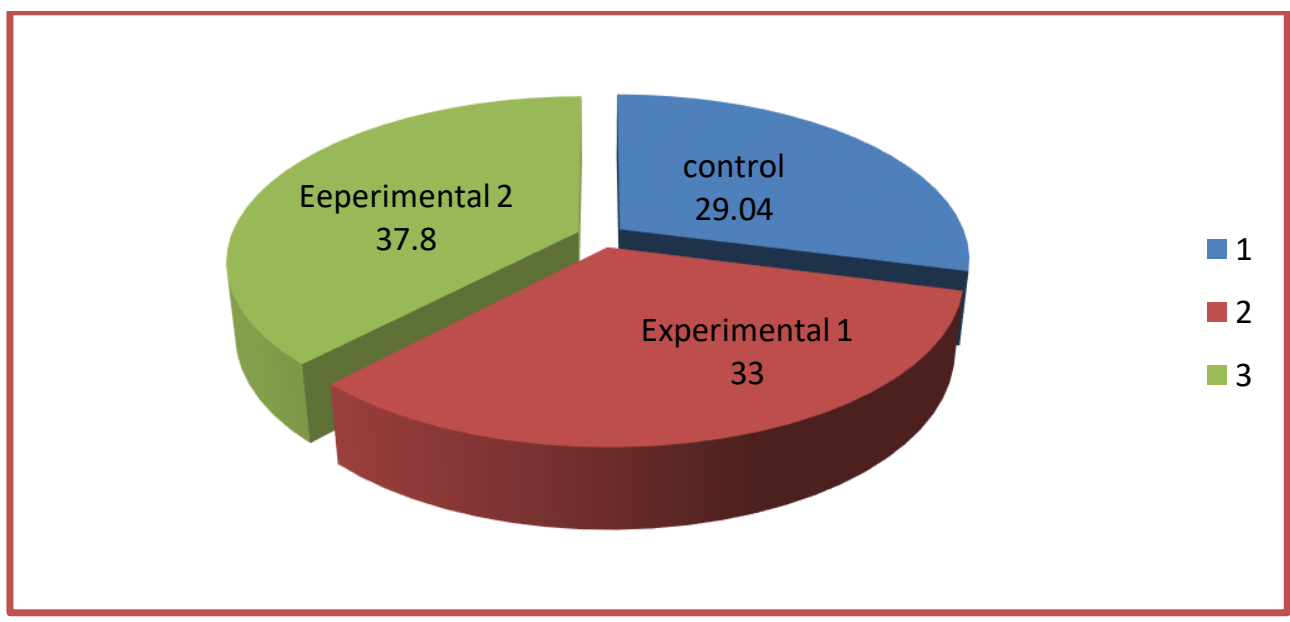

Figure 2

The Mean Score of the Study Groups in the Post-written Test

Table (4) shows the post-test results of the variance $(F)$ of for the three research groups, where the sum of squares between groups was (690.107) at a degree of freedom (2.000), and the average of the squares between the groups was (345.053).The sum of the squares within groups was (4158.880) with a degree of freedom
$(72,000)$, whereas average value of quarters within the groups reached (57.762). The computed $\mathrm{f}$ - value is higher than the tabulated value (3.12) at the level of significance (0.05) and freedom degree of (2. 72). This indicates that that the difference is significant among the three study groups.

Table 4: AVOVA Results of the Three Study Group in the post-test

\begin{tabular}{|l|l|l|l|l|l|l|l|}
\hline no & variable & The & Sum of & df & Mean & F- value & Sig. \\
\hline
\end{tabular}




\begin{tabular}{|c|c|c|c|c|c|c|c|c|}
\hline & & $\begin{array}{c}\text { source of } \\
\text { the } \\
\text { contrast }\end{array}$ & Squares & & Square & Computed & Tabulated & at 0.05 \\
\hline \multirow{3}{*}{1} & \multirow{3}{*}{ 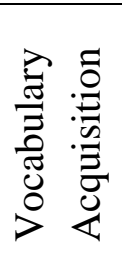 } & $\begin{array}{l}\text { Between } \\
\text { Groups }\end{array}$ & 690.107 & 2.000 & 345.053 & \multirow[t]{3}{*}{5.974} & \multirow[t]{3}{*}{3.12} & \multirow[t]{3}{*}{0.004} \\
\hline & & $\begin{array}{l}\text { Within } \\
\text { Groups }\end{array}$ & 4158.880 & 72.000 & 57.762 & & & \\
\hline & & Total & 4848.987 & 74.000 & & & & \\
\hline
\end{tabular}

Table (5) shows the least significant differences among the three groups of the study. It becomes evident that there is a significant difference between (the control group - experimental group 1) at the level of significance (0.031) and (the control group - experimental group 2) at the level of significance $(0,000)$ and a significant difference between (experimental group 1 - experimental group 2) at a significance level (0.008). As the table shows that the highest mean difference was between (control group - experimental group 2), since it reached (8.840), followed by (experimental group 1 - experimental group 2), as it reached (4.880), followed by (control group experimental group 1) as It reached (3.960).

Table 5: Least Significant Differences (LSD) among the Three Study Groups in the Written PostTest

\begin{tabular}{|c|c|c|c|c|c|c|c|c|}
\hline \multirow{2}{*}{ no } & Variable & \multicolumn{2}{|c|}{ Intermediate tests } & \multicolumn{2}{c|}{ Mean } & $\begin{array}{c}\text { Mean } \\
\text { Difference }\end{array}$ & $\begin{array}{c}\text { Std. } \\
\text { Error }\end{array}$ & Sig. \\
\hline \multirow{2}{*}{$\begin{array}{c}\text { Vocabulary } \\
\text { Acquisition }\end{array}$} & Control & $\begin{array}{c}\text { Experimental } \\
1\end{array}$ & 29.040 & 33.000 & $-3.96000^{*}$ & 1.796 & 0.031 \\
\cline { 3 - 9 } & & $\begin{array}{c}\text { Experimental } \\
1\end{array}$ & $\begin{array}{c}\text { Experimental } \\
2\end{array}$ & 29.040 & 37.880 & $-8.84000^{*}$ & 1.796 & 0.000 \\
\hline
\end{tabular}

1.There is no significant impact of using PowerPoint presentations on first intermediate Iraqi EFL learners' acquisition of vocabulary.

In order to verify the first hypothesis, mean differences of the Post- test between the experimental group 1 and the control group has been found. The results show that the difference between the two groups is significant in favour of the experimental group 1 (see Table 4 and Table 5). This indicates that PowerPoint presentations have a positive impact on Iraqi EFL learners' vocabulary acquisition. Accordingly, the first hypothesis is rejected.
2. There is no significant impact of using YouTube videos on first intermediate Iraqi EFL learners' acquisition of vocabulary.

In order to verify the second hypothesis, mean paired differences between the experimental group 2 (taught vocabulary by using YouTube videos ) and control group is found in the post-test (see Table 5 and 6). The results illustrate that difference between the two groups is significant in favour of the experimental group 2. This indicates that YouTube videos have a positive impact on Iraqi EFL learners' vocabulary acquisition. Thus, the second hypothesis is rejected. 
3. There is no significant difference between the experimental group 1 and the experimental group 2 in the acquisition of vocabulary.

Table 4 and 5 illustrate that there is a significant difference between the experimental group 1 and the experimental group 2 in favour of the second one, but that difference is approximate. Thus, it is indicated that both techniques used in this study are vital and they have a significant positive impact on improving Iraqi EFL learners' vocabulary acquisition level. Accordingly, the third hypothesis is rejected.

\section{Discussion}

The aim of the current study is to trace the effectiveness of using two techniques, namely PowerPoint Presentations and YouTube videos on Iraqi EFL intermediate learners' vocabulary acquisition by comparing their effects with traditional methods of teaching vocabulary. The results of the comparison between the pre- and post- test of the experimental group 1 show that there is a significant impact for the use of PowerPoint presentations on learners' vocabulary acquisition. The positive effectiveness of this technique might be related to the interesting and lively slides created by the researchers. They are full of colourful images, sounds, and animated texts that may help in gaining their attention to the lexical items presented. Leaners were interactive, interested and getting fun when they were presented with new vocabulary.

The importance of multimedia in helping learners to get incidental automatic control for the information presented, stimulated the researchers to trace the impact of another technique of multimedia on learners' vocabulary acquisition, that is, YouTube videos. The results obtained when comparing the mean scores pre-and post-test of the experimental group illustrate that using YouTube videos has a positive impact on learners' level of vocabulary acquisition. YouTube videos assisted students to know, comprehend, and retain the vocabulary items required. The reason behind that might be attributed to what theorized by multimedia theory that presenting content in
YouTube videos where both auditory and visual senses are engaged and integrated at the same time, may constitute an effective method of teaching than just through teaching by using one these senses. Moreover, teaching vocabulary through YouTube videos may create a positive interesting environment that can stimulate them to focus on the content and meanings of the targeted lexical items.

The result of the minor dominance of the experimental group 2 upon the experimental group 1 might be justified by the researchers by referring to the multidimensionality of the YouTube videos. YouTube videos offer learners numerous chances for learning new vocabulary. The new lexical items were offered in different forms such as spoken material, songs, debates...etc, where the integration of the scenes, feelings, animations altogether may create a motif for them to retain the targeted vocabulary items.

It can be said that this study provide another proof that multimedia has a positive impact on Leaners' vocabulary acquisition. The present study results come in agreement with the results of the previous studies of Chun and Plass (1996), Hai-peng and Li-jing (2007), Zarei and Gilanian (2013), Mahmoudzadeh (2014), and Azari and Giahpoor(2016). It added another evidence that multimedia has a positive impact on EFL learners vocabulary acquisition.

\section{Conclusions and Recommendations}

This study is to investigate the impact of two multimedia techniques, namely, PowerPoint presentations and YouTube videos on vocabulary acquisition of Iraqi EFL learners in comparison with traditional methods of teaching vocabulary. Through overall picture emerging from comparing the learners' the post- test mean scores, the researchers concluded that that the use of these two techniques in teaching vocabulary has an influential role in incidental vocabulary acquisition. The second experimental group, taught by vocabulary by using YouTube videos, shows a positive impact more than the control 
one, and also more than the first experimental one taught by the use of PowerPoint Presentations. The researchers found that presenting authentic YouTube videos in which information is presented to learners visually and aurally simultaneously is very helpful in improving EFL learners' vocabulary acquisition level. YouTube videos help to motivate them to interact with the content of the lexical items presented, to be more engaged and consequently to retrieve the information from memory in an automatic way. Though the first experimental group taught vocabulary through the PowerPoint Presentations shows less vocabulary acquisition level than the second one, but still the results indicate that PowerPoint presentations have a significant impact of EFL learners' vocabulary acquisition as compared with the control group that studies vocabulary by using the traditional methods. The researchers of the study recommend that EFL teachers should be well- trained and informed about using multimedia in their classrooms. EFL learners need to be exposed to new vocabulary in different forms and contexts to develop their receptive and productive skills.

\section{References}

[1] Afzal, N. (2019). A study on vocabularylearning problems encountered by BA English majors at the university level of education. Arab World English Journal, 10(3), 81-98.

[2] Alqahtani,M.(2015). The Importance of Vocabulary in Language Learning and How to be Taught. International Journal of Teaching and Education. Vol. 3( 3), 2134.

[3] Arndt, H. L., \& Woore. R. (2018).Vocabulary learning from watching YouTube videos and reading blog posts. Language Learning \& Technology, 22(1), 124-142. https://doi.org/10125/44660

[4] Azari, F., Giahpoor, H.(2016). The effect of multimedia glosses on vocabulary development of intermediate efl learners. Journal

[5]

of Arts \& Language Studies, 1(1),1-7.

[6] Chun, D.M. \& Plass, J.L. (1996). Effects of Multimedia Annotations on Vocabulary Acquisition. Modern Language Journal, 80(2),. 183-198.

[7] Coady, J. (1997). L2 vocabulary acquisition through extensive reading. In J. Coady \& T. Huckin (Eds.), Second language vocabulary acquisition: A rationale for pedagogy (pp. 225-237). Cambridge: Cambridge University Press.

[8] Hai-peng, H., \& Li-jing, D. (2007). Vocabulary acquisition in multimedia environment. US-China Foreign Language, 5(8), 55-59.

[9] Heriyanto, D. (2015). The effectiveness of using YouTube for vocabulary mastery. IJEE, 6(1), 1-12.

[10] Hulstijn, J. H. (2013). Incidental learning in second language acquisition. In C. A. Chapelle (Ed.), The encyclopedia of applied linguistics. Oxford, England: Wiley Blackwell.

[11] Idries, H.B.(2016). Investigating the Use of Power Point in Teaching English Vocabulary at Secondary Schools(Unpublished M.A. thesis in ELT). Retrieved at: http://repository.sustech.edu/bitstream/han dle/123456789/14578/Investigating\%20th e\%20Use\%20...\%20.pdf?sequence $=1 \&$ is A llowed=y

[12] Kabooha, R., \& Elyas, T. (2018). The effects of YouTube in multimedia instruction for vocabulary learning: Perception of EFL students and teachers. English Language Teaching, 11(2), 72-81. http://doi.org/10.5539/elt.v11n2p72

[13] Kanellopoulou, C.; Kermanidis, K.L.; Giannakoulopoulos, A. (2019). The DualCoding and Multimedia Learning Theories: Film Subtitles as a Vocabulary Teaching Tool. Educ. Sci., 9 (210), 1-13. https://doi.org/10.3390/educsci9030210 
[14] Liaskos, J., \& Diomidus, M. (2002). Multimedia Technologies in Education. Students Health Technology Inform, 65, 359-372.

[15] Lin, L.-F. (2010). English Learners' Incidental Vocabulary Acquisition in the Video-based CALL Program. Special issue of the Asian EFL Journal, 12(4), 51-66.

[16] Mahmoudzadeh S. (2014). The Effect of Using PowerPoint on Iranian EFL Learners . Procedia - Social and Behavioral Sciences, 98, 1077 - 1084.

[17] Mayer, R.(2001). Multimedia Learning. New York: Cambridge University Press.

[18] Mayer, R.E., (2009). Multimedia learning (2nd ed.). New York: Cambridge University Press.

[19] Mayer, R. E. (Ed.). (2014). The Cambridge handbook of multimedia learning. New York, NY: Cambridge University Press. https://doi.org/10.1017/CBO97811395473 $\underline{69}$

[20] Nader Assadi, Saeedeh Mozafari (2012) .Investigating the impact of computerassisted teaching on Iranian EFL vocabulary learning, International Journal of Asian Social Science, 2( 6), 881-889.

[21] Najjar, L., J., (1996). Multimedia Information and Learning. Journal of Educational Multimedia and Hypermedia, 5 (2), 129-150. Retrieved at: http://citeseerx.ist.psu.edu/viewdoc/downl oad?doi=10.1.1.118.1654\&rep=rep1\&type $=$ pdf

[22] Nouri H. and Shahid. A. (2005) The Effect of PowerPoint Presentations on Student Learning and Attitudes, Global Perspectives on Accounting Education, 2 (1), 53-73.

[23] Paivio, A. (1990). Mental representations: A dual coding approach. New York: Oxford University Press.

[24] Radanov, L. (2008). PowerPoint presentations in EFL classroom: power point or a challenge? English Language
Teachers' Association News Letters.

Retrieved at:

https://www.britishcouncil.rs/

[25] Sadoski, M. (2005). A dual coding view of vocabulary learning. Reading and Writing Quarterly, 21(3), 221-238.

[26] Simkins, M., Cole, K., Tavalin, F., \& Means, B. (2002). Increasing Student Learning Through Multimedia Projects. ASCD, Alexandria.

[27] Sok, S. (2014). Deconstructing the concept of 'incidental' L2 vocabulary learning. TESOL \& Applied Linguistics, 14(2), 21-37.

[28] Thao, V. T. (2003). The contribution of multimedia tools to EFL settings unfamiliar with technology. Asian EFL Journal, 5(3), 1-14.

[29] Zahedi, Y. and Abdi, M.(2012) The effect of semantic mapping strategy on EFL learners' vocabulary learning. Procedia Social and Behavioral Sciences, 69, 2273 -2280 .

[30] Zarei, A. A., \& Gilanian, M. (2013). The effect of multimedia modes on L2 vocabulary learning. International Journal of Management and Humanity Sciences, 2, 1011-1020. 